\title{
A Preliminary Study of Nutrition and Physical Activity Habits of Women with Physical Disabilities
}

\author{
Debra M. Harris \\ California State University, Fresno
}

\begin{abstract}
This article examines the behavioral habits of women with physical disabilities six months after a didactic and experiential three-hour training session regarding healthy nutrition and physical activity. It includes these women's perceptions of supportive factors and barriers to healthy nutrition and physical activity. All of the women made behavioral changes as a result of the training. They face more barriers than support in continuing with these changes. Access to healthy nutrition and physical activity continues to be problematic. Doorways, aisles, and sidewalks were problems noted as barriers.

(c) 2006 Californian Journal of Health Promotion. All rights reserved.

Keywords: women's health, disabilities, nutrition, physical activity
\end{abstract}

\section{Introduction}

Approximately one in five women in the United States lives with a disability (National Center on Birth Defects and Developmental Disabilities, 2004). According to the National Institute on Disability and Rehabilitation Research, 28.6 million females have disabilities, or $21.3 \%$ of the female population in the United States (Jans \& Stoddard, 1999). According to the United States Department of Health and Human Services, people with disabilities are less likely than those without disabilities to report moderate physical activity (Health Promotion, 2000).

People with disabilities report higher incidences of being overweight (Center for Disease Control and Prevention, n.d.). Forty percent of people with disabilities age 20 years and older reported being overweight compared with $35 \%$ of the general populations. Also, people with disabilities showed a decline in the amount of physical activity engaged in from 35\% in 1985 to $29 \%$ in 1995 (U. S. Department of Health and Human Services, 2000).

Women with physical disabilities encounter numerous challenges to maintaining overall physical health. They develop health problems in conjunction with their disability. Research regarding this problem is limited (Taylor, Baranowski, \& Young, 1998).

Women with physical disabilities encounter numerous challenges to maintaining their overall physical health. One of the biggest challenges is the stress that results from living in a society that imposes many limitations on them. Environmental barriers often restrict them from socializing and participating in community functions. Nosek et al. (2004) observed that women with physical disabilities feel limited in the places they can go and the people with whom they socialize. They must think about whether they can negotiate the environment based on adequate accommodations (Nosek et al., 2004).

Blinde and McCallister (1999) found that women participate in physical fitness programs because it helps them enhance their view of their capabilities. Physical activity helped them to view their bodies as a source of strength, rather than a weakness. They also benefited from the socialization during the activity.

In a study conducted with women with physical disabilities, most women met the Body Mass Index criterion for obesity (Jones \& Bell, 2004). Obesity contributes to a variety of health 
problems. The problems include elevated cholesterol, high blood pressure, cardiovascular problems, and diabetes (Center for Disease Control and Prevention, n.d.; Krummel, Koffman, Bronner, Davis, Greenland, Tessaro, 2001; Stampfer, Hu, Manson, Rimm, \& Willett, 2000).

The purpose of this study was two fold. First, it was to evaluate the behavioral outcomes of nutrition and physical activity training six months following the training. Second, it was meant to identify the positive and negative factors associated with maintaining healthy nutrition and physical activity in the community for women with physical disabilities.

\section{Method}

During the month of July, six women attended a three hour training session aimed at improving their overall health through improved healthy eating and physical activity. This was both didactic and experiential. During the first hour didactic information was presented regarding the food guide pyramid, portion sizes, and nutrient content of foods. This included providing the participants with the information verbally by nutritionist, accompanied by an educational film. A variety of visual displays were used during this time which included the effects of obesity on the body, the food guide pyramid, sugar content display, salt content display, and a portion size display. These items were passed to the participants for their appraisal so they could be as engaged as possible in the assimilation of the didactic information.

Following this didactic information presentation, two experiential opportunities were offered to the group. First, the nutritionist provided a cooking demonstration which reinforced the didactic presentation. This was done by explaining the contents of the food, food's effect on the body, and portion sizes. The result of the cooking demonstration was a healthy meal. Second, the participants and trainers ate a family style meal together which provided an opportunity for the participants to ask questions in a casual setting.
During the third hour, information regarding physical activity was provided by an individual with a degree in kinesiology, including the benefits of physical activity and accommodations needed for exercise. This was followed with participating in an activity that could be performed at home, typically from a sitting position. All the participants left with a cookbook and exercise pamphlet.

During the month of January, all of the participants were called in order to assess whether the training had changed their nutrition and physical activity related behavior. During this telephone interview, the participant was also asked about the positive and negative factors they encounter in the community that were related to nutrition and physical activity. Each telephone conversation lasted a minimum of 45 minutes.

\section{Instrument}

A structured interview guide was used to interview each participant on the telephone. The following open ended questions were asked:

1. Did you benefit from the training six months ago?

2. Since your participation in the training six months ago, have you made any changes related to eating healthier?

a. If yes, what changes have you made?

3. Since your participation in the training six months ago, have you made any changes related to your activity level?

a. If yes, what changes have you made?

4. What positive factors support you eating healthy?

5. What are the barriers to eating healthy?

6. What positive factors support you being physically active?

7. What are the barriers to being physically active?

\section{Participants}

The six women who participated in the study ranged in age from 29 to 59 years, with an average age of 46. Two of the participants identified themselves as Hispanic, two as Caucasian, and two as other. Two participants identified themselves as graduated from high 
school, two had some college experience, and two graduated from college. Their physical disabilities included degenerative muscular disease, multiple sclerosis, diabetes, arthritis, and peripheral neuropath.

\section{Findings}

These responses from the participants are organized under two major topics, nutrition and physical activity. Each topic contains major themes that emerged from the interviews, which include any behavior changes made that resulted from the training, supportive factors to continuing this behavior change, and barriers to continuing this behavior change. This discussion includes comments from the women regarding these topics.

\section{Nutrition}

Behavioral Change. Table 1 contains the study findings related to nutrition. All six women indicated they benefited from the training regarding healthy eating. All of the women stated they had made behavioral changes as the result of the training. All of the women stated they had been eating more fruits and vegetables during the six months since they attended the training. Two participants, or 33\%, believed the training helped them to eat leaner meats, such as baked chicken instead of beef. Two women, or $33 \%$, also indicated they had stopped drinking regular sodas due to the sugar content they learned about. Comments made include the following: "I have lost 20 pounds since the training just by limiting the amount of sugar I eat" and "I have really cut down on sugar and carbohydrates which has helped my diabetes."

Table 1

Participant Results Related to Nutrition (Behavior Change, Supportive Factors, and Barriers) $(\mathrm{N}=6)$

\begin{tabular}{|l|c|c|}
\hline \multicolumn{1}{|c|}{ Major Finding } & N & Percent \\
\hline Behavior Change & & \\
\hline Benefited from Training & 6 & 100 \\
\hline Behavioral Change & 6 & 100 \\
\hline Increased Fruits & 6 & 100 \\
\hline Increased Vegetables & 6 & 100 \\
\hline Eat Leaner & 2 & 33 \\
\hline Soda Intake Decreased & 2 & 33 \\
\hline Supportive Factors & & \\
\hline Improved Eating of Fast Food & 3 & 50 \\
\hline Barriers & & \\
\hline Media Promotion of Fast Food & 2 & 33 \\
\hline Grocery Store Access & 4 & 67 \\
\hline Restaurant Access & 6 & 100 \\
\hline
\end{tabular}

Supportive Factor. The supportive factor that helps these women with physical disabilities to eat healthier is listed in Table 1 . Three participants, or $50 \%$, stated that although they continue to eat food from fast food restaurants, they make healthier menu choices when they order. One participant stated "I know now what the contents of the food are and I watch what I eat based on the content, not just what looks good.”

Barriers. Two participants stated that it is difficult to resist eating at fast food restaurants because they are widely advertised in the media. Shopping at a grocery store was found to be difficult for sixty seven percent, or four, of the 
women because the aisles are not wide enough for a wheelchair or a scooter. Items located on the upper shelves are not in reach. All indicated they had problems eating in restaurants because the aisles were not wide enough and the tables were not always high enough to accommodate their wheelchair or scooter. Comments made include: "it is hard to resist the constant advertising of fast food on TV"; "I spend a lot of time watching television and that is what I see being advertised"; and also "in the winter time it is hard to eat fruits and vegetables." One respondent stated "it is hard to go through a standard doorway at a local restaurant where they offer healthier foods" and "the tables are too close together to accommodate my scooter." One participant stated "it is hard to shop in the grocery store because I need help reaching items on the top shelves and I don't want to bother anyone to help me.”

\section{Physical Activity}

Behavioral Change. Table 2 contains the findings regarding this section. All the women believed they benefited from the training relative to physical activity. All of the participants indicated they had increased their physical activity as a result of the training. Their activities included swimming and stretching. They all stated they had the booklet regarding upper body exercises and were using the arm exercises. Sixty seven percent, or four out of six, stated they had begun exercising on a daily basis.

Table 2

Participant Results Related to Physical Activity (Behavior Change, Supportive Factors, and Barriers) $(\mathrm{N}=6)$

\begin{tabular}{|l|c|c|}
\hline \multicolumn{1}{|c|}{ Major Finding } & N & Percent \\
\hline Behavior Change & & \\
\hline Benefited from Training & 6 & 100 \\
\hline Behavioral Change & 6 & 100 \\
\hline Exercise Daily & 4 & 67 \\
\hline Supportive Factors & & \\
\hline None & 0 & 0 \\
\hline Barriers & & \\
\hline No Appropriate Gyms & 3 & 50 \\
\hline Poor Sidewalks & 4 & 67 \\
\hline No Sidewalks & 4 & 67 \\
\hline
\end{tabular}

Supportive Factor. None of the women could state any supportive factors related to physical activity.

Barriers. Table 2 summarizes the findings relative to barriers to physical activity. Fifty percent $(n=3)$, of the participants stated that there were no exercise gyms that could accommodate them. Sixty seven percent $(n=4)$, women stated that the sidewalks they use with their wheelchair or scooter are not in good repair and could cause them to fall onto the sidewalk. One participant who did belong to a gym does not exercise there very often because "no one can help me use the different machines so I don't go as often as I can." "I also feel isolated and I think it would be better if I had more contact with people.” Another participant stated that "there are no places for people who are amputees to go and exercise, so I have to depend on physical therapy now.” Four participants, or $67 \%$, stated "the sidewalks are too bumpy for my scooter to get over." Four, or $67 \%$, explained that "some roads have no sidewalks." 


\section{Conclusions}

The findings of this study indicate that training can have a desired effect on behavior change, at least for six months following training. After six months of the training, all six women with disabilities had made changes in their nutrition and physical activity habits. It is uncertain whether this behavior change is permanent, due to the short follow-up period.

Changes in nutritional habits seemed to be easier than changes in physical activity habits. There were no supportive factors these women could think of related to physical activity. All of the barriers were out of their personal control to change. These problems require large scale community change.
In general, access to healthy nutrition and physical activity is problematic. Environmental problems related to doorways, aisles, and sidewalks were evident. These women understand the importance of nutrition and physical activity but can not access the services they need.

\section{Future Research}

Further research is needed with a larger sample of individuals with physical disabilities. It would lend credibility to a study to use both males, as well as females, to the study. Because of the small sample size in this study, caution must be used when generalizing the findings to the general population. Participants of a larger sample could expand on the supportive factors and barriers to nutrition and physical activity.

\section{References}

Blinde, E. M., \& McCallister, S. G. (1999). Women, disability, and sport and physical fitness activity: The intersection of gender and disability dynamics. Research Quarterly for Exercise and Sport, 70, 1-12.

Centers for Disease Control and Prevention. (n.d.). Physical activity and good nutrition: Essential elements for good health-at-a-glance. Retrieved October 24, 2000, from http://www.cdc.gov/ncedphe

Health Promotion (2000). General information on physical activity. Retrieved October 24, 2005, from http://www.crowdbcm.net/healthpromotion/Phys Act-gen.htm

Jans, L., \& Stoddard, S. (1999). Chartbook on women and disability in the United States. An InfoUse report. Washington, DC: U.S. National Institute on Disability and Rehabilitation Research.

Jones, G. C., \& Bell, K. (2004). Adverse health behaviors and chronic conditions in working age women with disabilities. Family Community Health, 27, 22-36.

Krummel, D. A., Koffman, D. M., Bronner, Y., Davis, J., Greenlund, K., \& Tessaro, I. (2001). Cardiovascular health interventions in women: What works? Journal of Women's Health \& Gender Based Medicine, 10, 117-136.

National Center on Birth Defects and Developmental Disabilities. (2004). Women with disabilities. Retrieved October 25, 2005, from http://www.cdc.gov/ncbddd/women/default.htm

Nosek, M. A., Hughes, R. B., Howland, C. A., Young, M. E., Mullen, P. D., \& Shelton, M. L. (2004). The meaning of health for women with physical disabilities. Family Community Health, 27, 6-21.

Stampfer, M. J., Hu, F. B., Manson, J.E., Rimm, E. B., \& Willett, W. C. (2000). Primary prevention of coronary heart disease in women through diet and lifestyles. New England Journal of Medicine, 343,16-22.

Taylor, W. C., Baranowski, T., \& Young, D. R. (1998). Physical activity intervention in low income, ethnic minority, and populations with disability. American Journal of Preventive Medicine, 15, 334-343.

U. S. Department of Health and Human Services. (2000). Healthy people 2010: Understanding and improving health and objectives for improving health. Washington, DC: U. S. Government Printing Office. Retrieved October 25, 2005, from http://www.healthypeople.gov/Document/HTML/Volume1/06Disability.htm 


\section{Acknowledgements}

Thanks to Linda Negrete, Graduate Student at California State University, Fresno, for assistance with data collection.

$\underline{\text { Author Information }}$

Debra M. Harris, Ph.D.

Associate Professor

California State University, Fresno

1364 Oak Avenue

Clovis, CA 93611

Ph.: 559-297-1627

E-Mail: dharris@csufresno.edu 